\title{
Regulation of the Escherichia coli csgD promoter: interplay between five transcription factors

\begin{abstract}
Correspondence
Akira Ishihama

aishiham@hosei.ac.jp
\end{abstract} \\ Received 18 February 2010 \\ Revised 7 May 2010 \\ Accepted 10 May 2010

\author{
Hiroshi Ogasawara, ${ }^{1}$ Kayoko Yamada, ${ }^{1}$ Ayako Kori, ${ }^{1}$ \\ Kaneyoshi Yamamoto ${ }^{1,2}$ and Akira Ishihama ${ }^{1,2}$ \\ ${ }^{1}$ Department of Frontier Bioscience, Hosei University, Koganei, Tokyo 184-8584, Japan
${ }^{2}$ Research Center for Micro-Nano Technology, Hosei University, Koganei, Tokyo 184-8584, Japan
} \\ Under stressful conditions in nature, Escherichia coli forms biofilms for long-term survival. Curli fimbriae are an essential architecture for cell-cell contacts within biofilms. Structural components and assembly factors of curli are encoded by two operons, csgBA and $\operatorname{csg} D E F G$. The csgD gene product controls transcription of both operons. Reflecting the response of $\operatorname{csg} D$ expression to external stresses, a number of transcription factors participate in the regulation of the $\operatorname{csg} D$ promoter. Analysis of the $\operatorname{csg} D$ mRNA obtained from $E$. coli mutants in different transcription factors indicated that $\mathrm{CpxR}$ and $\mathrm{H}-\mathrm{NS}$ act as repressors while OmpR, RstA and IHF act as activators. An acid-stress response regulator, RstA, activates $\operatorname{csg} D$ only under acidic conditions. These five factors bind within a narrow region of about $200 \mathrm{bp}$ upstream of the csgD promoter. After pair-wise promoter-binding assays, the increase in $\operatorname{csg} D$ transcription in the stationary phase was suggested to be due, at least in part, to the increase in IHF level cancelling the silencing effect of $\mathrm{H}-\mathrm{NS}$. In addition, we propose a novel regulation model of this complex $\operatorname{csg} D$ promoter through cooperation between the two positive factors (OmpR-IHF and RstA-IHF) and also between the two negative factors (CpxR-H-NS).
}

\section{INTRODUCTION}

Bacteria can switch from a single-cell planktonic growth mode to a multicellular community (biofilm) mode. During such a growth transition state, cell morphology, physiology and metabolism are markedly altered (PrigentCombaret et al., 2001; Schembri et al., 2003; Beloin et al., 2004; Ren et al., 2004). In single-cell growth mode, cell motility using flagella is critical for adaptation to environments. The master regulator FlhCD complex plays a key role in controlling transcription of a set of genes for flagella formation (Claret \& Huges, 2000). When Escherichia coli cells switch their life mode from single planktonic cell growth to multicellular community (biofilm) mode, the genetic system for flagella formation is turned off and the genes involved in cell-cell adhesion are activated. The biofilm matrix is a complex architecture of cell aggregates that are attached on the surface of inorganic solid materials in nature or on eukaryotic tissues in host animals. After a comprehensive analysis of a set of E. coli mutants, each lacking one of 3985 non-essential genes, a total of 110 genes were indicated to be involved in biofilm formation (Niba et al., 2007).

During biofilm development, curli fimbriae, the major biofilm component, play a key role in both initial adhesion to solid surfaces and subsequent cell-cell interactions (Vidal et al., 1998; Chapman et al., 2002; Prigent-Combaret et al., 2000). Curli fimbriae also mediate bacterial adhesion to host cells and invasion, and activation of both the proinflammatory response and the immune system (Bian et al., 2000; Zogaj et al., 2001). Accordingly, curli participate in virulence phenotypes (Hammar et al., 1995; Vidal et al., 1998; Bian et al., 2000; Gophna et al., 2001; Cookson et al., 2002). A set of polysaccharide polymers such as colanic acid and cellulose are also involved in the formation of cell aggregates and their attachment to solid surfaces, together leading to biofilm formation (Arnqvist et al., 1994; Prigent-Combaret et al., 2001; Sutherland, 2001; Zogaj et al., 2001; Wang et al., 2004). Co-production of curli and polysaccharides is required for efficient biofilm formation (Prigent-Combaret et al., 2000; Zogaj et al., 2001). Interestingly, bacterial curli fibres share biochemical and structural characteristics with eukaryotic amyloid fibres and thus provide a model system for understanding amyloid fibre formation (Wang et al., 2007).

Genes for curli formation are organized in two adjacent divergently transcribed operons: $\operatorname{csg} B A$, encoding the structural components, and $\operatorname{csg} D E F G$, encoding proteins for curli assembly and transport (Loferer et al., 1997). Between two operons, there is one of the largest intergenic spacers in the E. coli genome without coding capacity; it is $755 \mathrm{bp}$ in length with unique features such as high curvature and low stability (Pedersen et al., 2000). Expression of the curli operons is under the control of 
the $\mathrm{CsgD}$ protein, the first gene product of the csgDEFG operon (Hammar et al., 1995). The CsgD protein, a FixJ/ LuxR-family transcription regulator, modulates the expression of not only the csg operon but also a set of genes for adaptation of cell physiology to the biofilm life style (Chirwa \& Herrington, 2003; Brombacher et al., 2006), including bapA, encoding a large secreted protein (Latasa et al., 2005), and $a d r A$, encoding the enzyme for synthesis of cyclic di-GMP, a bacterial second messenger (Simm et al., 2004) for enhancement of cellulose production (Romling et al., 2000; Zogaj et al., 2001). The positive regulation of cellulose production by $\mathrm{CsgD}$ is mediated through the transcriptional regulation of $a d r A$. In turn, the AdrA protein activates cellulose synthesis at a post-transcriptional level by controlling the synthesis of c-di-GMP. CsgD also regulates yoaD, encoding one of the c-di-GMP phosphodiesterases (Brombacher et al., 2006), suggesting that CsgD is involved in control of the intracellular level of c-di-GMP. So far CsgD-binding sites have been identified in the CsgDdependent $\operatorname{csg} B$, adrA and pepD promoters (Brombacher et al., 2003). CsgD upregulates $g l y A$ to facilitate the synthesis of curli, which contain more glycine than normal E. coli proteins (Chirwa \& Herrington, 2003). Deletion of the GlcNAc-6P deacetylase gene, nagA, results in decreased transcription from the curli-specific promoters, $c s g B A$ and csgDEFG, and a corresponding decrease in curli production (Barnhart \& Chapman, 2006). Disruption of nagC, encoding the regulator of nag operon for utilization of GlcNAc, leads to a reduction in curli production, while an increase in intracellular GlcNAc-6P level leads to downregulation of curli gene expression. Together, these observations indicate that $\mathrm{CsgD}$ is the master regulator of a set of genes for biofilm formation.

In concert with the complex mode of regulation for biofilm formation, the expression of $\operatorname{csg} D$ has been proposed to be under the control of various stress-sensing regulatory proteins such as OmpR (Romling et al., 1998; Vidal et al., 1998; Prigent-Combaret et al., 1999, 2000, 2001; Gerstel \& Romling, 2001; Gerstel et al., 2003), CpxR (PrigentCombaret et al., 2001; Jubelin et al., 2005), Crl (Bougdour et al., 2004; Robbe-Saule et al., 2006), CRP (Zheng et al., 2004), H-NS (Arnqvist et al., 1994; Gerstel et al., 2003; Olsen et al., 1993), IHF (Gerstel et al., 2003; Gerstel \& Romling, 2001), MlrA (Brown et al., 2001) and RcsB (Ferrieres \& Clarke, 2003; Vianney et al., 2005). Recently, we found that the phosphorelay network from the $\mathrm{Mg}$ (II)-sensing PhoQP to the low-pH-sensing RstBA is directly involved in regulation of the $\operatorname{csg} D$ promoter (Ogasawara et al., 2007a). At present, however, the molecular mechanisms of transcription regulation of the csg operons by so many transcription factors and possible interplay between these regulatory proteins remain totally unsolved. Knowledge of how multiple factors, each monitoring a specific environmental condition, influence $\operatorname{csg} D$ promoter activity could be a clue toward understanding the pathway of $E$. coli differentiation leading to formation of biofilm. We have therefore performed a systematic study of transcription regulation of a single $\operatorname{csg} D$ promoter by as many as 10 reported or predicted transcription factors.

In this report, we describe the regulatory modes of five transcription factors, CpxR, OmpR, RstA, IHF and H-NS, and their interplays in binding in vitro to the $\operatorname{csg} D$ promoter. Based on the results described herein, we propose a novel regulation model of cooperation between two positive factors (OmpR and IHF; and RstA and IHF) and also between two negative factors (CpxR and H-NS). On-going studies on the regulation of the $\operatorname{csg} D$ promoter by other regulators, CRP, Crl, RcsB and MlrA, will be described elsewhere.

\section{METHODS}

Bacterial strains. Escherichia coli $\mathrm{BL} 21(\mathrm{DE} 3)\left[\mathrm{F}^{-}\right.$ompT hsd $\left(\mathrm{r}_{\mathrm{B}}^{-} \mathrm{m}_{\mathrm{B}}^{-}\right)$ $d c m$ gal $\lambda(\mathrm{DE} 3)]$ was used for expression and purification of all the transcription factors examined in this study. E. coli K-12 wild-type BW25113 and single-gene knockout mutant strains, JW3368 (ompR), JW1702 (cpxR), JW3883 (rstA), JW1600 (ihfA), JW0895 (ihfB) and JW1225 ( hns), were obtained from the Keio collection in the National Bio-Resource Project (National Institute of Genetics, Japan). Cells were cultured in LB medium, YESCA medium (Pratt \& Silhavy, 1998) or low-phosphate minimal glucose medium (LPM) (Suziedeliene et al., 1999) supplemented with peptone $\left(0.6 \mathrm{mg} \mathrm{ml}^{-1}\right)$ and at $28{ }^{\circ} \mathrm{C}$ or $37^{\circ} \mathrm{C}$. When necessary, $100 \mu \mathrm{g}$ ampicillin $\mathrm{ml}^{-1}$ and $50 \mu \mathrm{g}$ kanamycin $\mathrm{ml}^{-1}$ were added to the medium.

Plasmid construction. For the construction of a lac $Z$ reporter vector, a DNA fragment (438 bp) containing the $\operatorname{csg} D$ promoter region was prepared by PCR using E. coli KP7600 genomic DNA as a template and primers csgD-EcoRI-F and csgD-BamHI-R2 (for sequences see Table 1). After digestion with EcoRI and BamHI, the PCR-amplified fragment was inserted into pRS551 (Simons et al., 1987 ) at the corresponding site to generate the plasmid pRScsgD. For construction of an arabinose-inducible NlpE expression plasmid, a DNA fragment $(774 \mathrm{bp})$ containing the NlpE-coding region was prepared by PCR using E. coli KP7600 genomic DNA as a template, with primers BAD-nlpE-EcoRIF and BAD-nlpE-XbaI-R (for sequences see Table 1). After digestion with EcoRI and XbaI, the PCR-amplified fragment was inserted into pBAD18 at the corresponding site to generate the plasmid pBADnlpE.

Expression and purification of transcription factors. All the transcription factors used in this study were overexpressed in and purified from E. coli as His-tagged forms except for IHF, which was purified in native form without His-tag as described previously (Murakami et al., 1996; Azam \& Ishihama, 1999; Yamamoto et al., 2005). For construction of plasmids for His-tagged transcription factors, pCpxR, pH-NS, pOmpR and pRstA, DNA fragments corresponding to the coding sequences of the respective transcription factors were amplified by PCR using E. coli W3110 genomic DNA as a template and pairs of primers (Table 1) designed to hybridize upstream or downstream of each coding sequence. After digestion with NdeI and NotI (note that the restriction enzyme sites were included within the primer sequence), PCR products were cloned into pET21a $(+)$ (Novagen) between the NdeI and NotI sites. The plasmid constructs were confirmed by DNA sequencing. For protein expression, the plasmids were transformed into E. coli BL21(DE3). Transformants were grown in $200 \mathrm{ml} \mathrm{LB}$ medium, and at a cell density of $\mathrm{OD}_{600} 0.6$, IPTG was added at a final concentration of $1 \mathrm{mM}$. After $3 \mathrm{~h}$ incubation, cells were harvested by centrifugation, 
Table 1. Primers

\begin{tabular}{|ll|}
\hline Primer & \multicolumn{1}{c|}{ Sequence $\left(\mathbf{5}^{\prime}\right.$ to $\left.\mathbf{3}^{\prime}\right)$} \\
\hline hns-F & GAGATTACTCATATGAGCGAAGC \\
hns-R & GCAATCTACAGCGGCCGCTTGCTTGATC \\
csgD-EcoRI-F & AGACAGGAATTCTTCTTGCCCGTCGCT \\
BAD-BamHI-R2 & CTGACAGGATCCTCTAAAATAGAAGCACCA \\
BAD-nlpE-XbaI-R & CAAGCGTGAATTCGATGCGCGGCAAAGTGC \\
CD1F & TATATCCTTCTAGACTGTTTTGCGTTTGTT \\
CD1R-FITC-R & AATATTTTTATATGCATTA \\
CD3F & CAATTTTAAAAAATCATACA ${ }^{*}$ \\
CD3R-FITC-R & TTAATAAAACCTTAAGGTTAA \\
CD6F & TTAAACATGTAACTAAATGT ${ }^{*}$ \\
CD6R-FITC-R & TTCTTGCCCGTCGCTGATTGCT \\
asr-F & GCACTGCTGTGTGTAGTAAT \\
asr-R & ATGAAAAAAGTATTAGCTCTGGTTGTTGC \\
ompC-F & CGGGTTGTGCAGCAGGTTTT \\
ompC-R & GCGGTTCTATCACTTATGATTACGAAG \\
cpxP-F & TTAGAACTGGTAAACCAGACCCAGA \\
cpxP-R & TCAACGCTGGCAGTCAGTTCATTAA \\
csgD-S & GGAACGTGAGTTGCTACTACTCAATA \\
csgD-T & TTATCGCCTGAGGTTATCGTTTGC \\
\hline
\end{tabular}

${ }^{\star}$ FITC label at $5{ }^{\prime}$ end.

washed with lysis buffer $\left(50 \mathrm{mM}\right.$ Tris/ $\mathrm{HCl}, \mathrm{pH} 8.0$ at $4{ }^{\circ} \mathrm{C}$, and $100 \mathrm{mM} \mathrm{NaCl}$ ), and then stored at $-80{ }^{\circ} \mathrm{C}$ until use.

For protein purification, frozen cells were lysed by treatment with lysozyme in lysis buffer containing $100 \mathrm{mM}$ PMSF followed by sonication for cell disruption. His-tagged transcription factors were affinity-purified from the supernatant fractions by use of a Ni-NTA agarose (Qiagen) column (Murakami et al., 1996; Yamamoto et al., 2005). The purity of purified transcription factors was checked by SDS-PAGE.

Gel mobility shift assay. The gel shift assay was performed as described previously (Ogasawara et al., 2007a, b). Briefly, probes were generated by PCR amplification of three $\operatorname{csg} D$ promoter regions, CD1, CD3 and CD6 (see Fig. 6 for their locations on the $\operatorname{csg} D$ promoter), using a pair of primers (Table 1), the pRScsgD DNA containing the recognition sequences for all the $\operatorname{csg} D$ promoter-binding transcription factors as template, and Ex Taq DNA polymerase (Takara). One of each primer pair was labelled with FITC (Table 1). PCR products were purified by PAGE. For gel shift assays, mixtures of the FITClabelled probes and purified transcription factors were incubated at $37{ }^{\circ} \mathrm{C}$ for $30 \mathrm{~min}$ in the gel shift buffer $(10 \mathrm{mM}$ Tris/ $\mathrm{HCl}, \mathrm{pH} 7.8$ at $4{ }^{\circ} \mathrm{C}, 150 \mathrm{mM} \mathrm{NaCl}$ and $3 \mathrm{mM}$ magnesium acetate). After addition of a DNA dye solution, the mixture was directly subjected to $4 \%$ or $6 \%$ PAGE. Fluorescently labelled DNA in gels was detected using the Pharos FX plus system (Bio-Rad).

DNase I footprinting assay. FITC-labelled probes ( 0.5 pmol each) were incubated at $37{ }^{\circ} \mathrm{C}$ for $30 \mathrm{~min}$ with various amounts of transcription factors in DNase I footprinting buffer $[25 \mu 110 \mathrm{mM}$ Tris/ $\mathrm{HCl}$ ( $\mathrm{pH} 7.8$ ), $150 \mathrm{mM} \mathrm{NaCl}, 3 \mathrm{mM}$ magnesium acetate, $5 \mathrm{mM}$ $\mathrm{CaCl}_{2}$ and $25 \mu \mathrm{g} \mathrm{BSA} \mathrm{ml}{ }^{-1}$ ]. After incubation for $30 \mathrm{~min}$, DNA digestion was initiated by the addition of $5 \mathrm{ng}$ of DNase I (Takara). After digestion for $30 \mathrm{~s}$ at $25{ }^{\circ} \mathrm{C}$, the reaction was terminated by the addition of $25 \mu \mathrm{l}$ phenol. Digested products were precipitated with ethanol, dissolved in formamide-dye solution, and analysed by electrophoresis on a $6 \%$ polyacrylamide gel containing $7 \mathrm{M}$ urea using the SHIMADZU slab gel electrophoresis system (DSQ-500L).

Northern blot analysis. For preparation of total RNA for Northern blot analysis, overnight cultures were diluted 100-fold with $30 \mathrm{ml}$ YESCA medium or LPM supplemented with peptone $\left(0.6 \mathrm{mg} \mathrm{ml}^{-1}\right)$ at either $\mathrm{pH} 7.0$ or $\mathrm{pH} 4.5$ and cells were incubated for 6 or $12 \mathrm{~h}$ (until late stationary phase) at $28{ }^{\circ} \mathrm{C}$. RNA purification (Ogasawara et al., 2007a, b) and Northern blotting (Shimada et al., 2007; Umezawa et al., 2008) were performed as described previously. The DIG-labelled DNA fragments were amplified by PCR using W3110 genomic DNA (50 ng) as template, DIG-11-dUTP (Roche) and dNTP as substrates, gene-specific forward and reverse primers, and Ex-Taq DNA polymerase (Takara). In brief, $4 \mu \mathrm{g}$ total RNA was incubated in formaldehyde-MOPS gel-loading buffer for $10 \mathrm{~min}$ at $65{ }^{\circ} \mathrm{C}$ for denaturation, separated by electrophoresis on formaldehyde-containing $2 \%$ agarose gel, and then transferred on to nylon membrane (Roche). Hybridization with a DIG-labelled probe was performed with the DIG easy Hyb system (Roche) at $50{ }^{\circ} \mathrm{C}$ overnight. For detection of the DIG-labelled probe, the membranes were treated with anti-DIG-AP Fab fragments and CDP-Star (Roche), and the images were scanned with LAS-4000 (Fuji Film). The product size on the membrane was estimated on the basis of migration of RNA markers (Toyobo).

Quantitative Western blot analysis. Intracellular concentrations of transcription factors were determined by using the quantitative Western blot system, which was employed for determination of sigma factors (Jishage et al., 1996; Maeda et al., 2000) and nucleoid proteins (Azam et al., 1999). Briefly, E. coli whole-cell lysates were prepared by sonication after lysozyme treatment, and treated with antibodies, which were prepared in rabbits against purified transcription factors, CsgD, RstA, OmpR, CpxR, IHF and H-NS. Immunoprecipitates were recovered with purified Protein-A and subjected to SDS-PAGE in parallel with various amounts of the respective purified proteins to make the standard curve. 


\section{RESULTS AND DISCUSSION}

\section{Promoter organization of the csgDEFG operon}

Transcription start site $\mathrm{P} 1$ of the $\operatorname{csg} D E F G$ operon has been identified at $148 \mathrm{bp}$ upstream of the $\operatorname{csg} D$ translation initiation codon in wild-type E. coli K-12 Y-mel cells grown in CFA agar for $48 \mathrm{~h}$ at $26^{\circ} \mathrm{C}$ (Hammar et al., 1995). In addtion, we identified another promoter, P2, $10 \mathrm{bp}$ downstream from P1 (Ogasawara et al., 2007a). These $\operatorname{csg} D$ promoters carry the typical feature of RpoDdependent promoters, but transcription of the $\operatorname{csg} D$ operon is functionally dependent on the stationary-phase-specific RpoS sigma factor as well as the major RpoD sigma factor (Hammar et al., 1995; Ogasawara et al., 2007a). RpoDdependent promoters are often recognized by not only RpoD but also RpoS sigma factors (Kolb et al., 1995; Tanaka et al., 1995).

CsgD expression leads to an increase in RpoS level in various ways (Ren et al., 2004; Gualdi et al., 2007). For instance, $\mathrm{CsgD}$ induces the expression of iraP, which encodes a stabilization factor of the RpoS sigma factor, by interfering with the RssB-mediated proteolysis of RpoS by the ClpXP protease (Bougdour \& Gottesman, 2007; Gualdi et al., 2007). Consequently, expression of a number of the RpoS-regulated genes is induced after CsgD expression (Lacqua et al., 2006; Gualdi et al., 2007).

\section{Transcription factors involved in regulation in vivo of the csgD promoter}

Expression of the curli operons, $\operatorname{csg} B A$ and $\operatorname{csg} D E F G$, is induced in response to various environmental stresses such as low temperature, low osmolarity and nutrient deficiency (for instance see Olsen et al., 1993). Under laboratory culture conditions in the absence of specific external stresses, the expression of $\operatorname{csg} D$ is low in the exponential growth phase but increases in the stationary phase as detected by Northen blot analysis (Fig. 1a). For regulation of the $\operatorname{csg} D$ promoter, more than 10 transcription factors have been indicated to be involved besides two sigma factors. Among these transcription factors, direct binding to the $\operatorname{csg} D$ promoter has been identified for five factors, CpxR (Jubelin et al., 2005), H-NS (Gerstel et al., 2003), IHF (Gerstel et al., 2003), OmpR (Vidal et al., 1998) and RstA (Ogasawara et al., 2007a). The influence of these five transcription factors on transcription in vivo from the $\operatorname{csg} D$ promoter was examined by Northern blot analysis for a set of mutants, each lacking one of these factors, cultured at $28{ }^{\circ} \mathrm{C}$ in YESCE medium, in which curli expression has been identified (Pratt \& Silhavy, 1998; Romling et al., 1998). In ompR, ihfA and ihfB mutants, $c s g D$ mRNA was not detected in either the exponential $(6 \mathrm{~h})$ or the stationary $(12 \mathrm{~h})$ phase (Fig. 1b, lanes 2, 5 and 6) [note that IHF is composed of an $\alpha-\beta$ heterodimer encoded by ihfA and ihfB, respectively], indicating that OmpR and IHF are the positive factors of the $\operatorname{csg} D$ promoter, in agreement with the previous studies (Vidal et al., 1998; Gerstel et al., 2003).

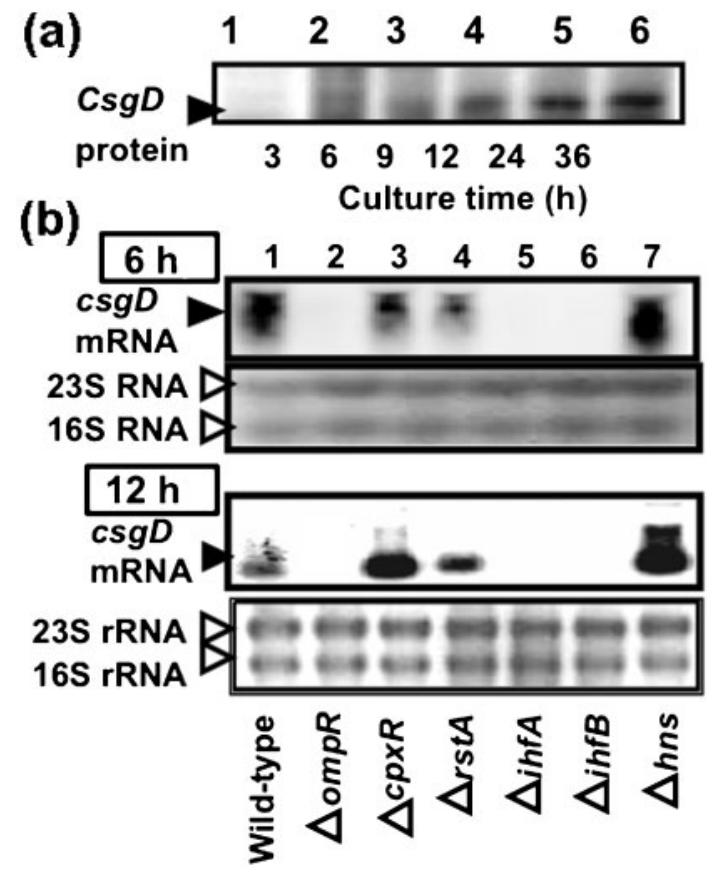

Fig. 1. Growth-phase-dependent expression of the $\operatorname{csg} D$ gene. (a) The intracellular concentration of CsgD protein was determined at various growth phases. Wild-type E. coli K-12 BW25113 was grown in YESCA medium at $28^{\circ} \mathrm{C}$. At the indicated times after transfer to fresh medium, whole-cell lysates were prepared and subjected to quantitative Western blot analysis using anti-CsgD antibodies. (b) The level of $\operatorname{csg} D$ mRNA in a set of mutants, each lacking the gene for one test transcription factor, was determined by Northern blot analysis. Overnight cultures of $E$. coli wild-type K$12 \mathrm{BW} 25113$ and the mutants indicated were grown at $28{ }^{\circ} \mathrm{C}$ for 6 or $12 \mathrm{~h}$ in YESCA medium. Total RNA was isolated from each culture, fractionated by PAGE and subjected to Northern blotting. $\operatorname{csg} D$ mRNA was detected with DIG-labelled $\operatorname{csg} D 3^{\prime}$ probe (upper panels) while rRNA was detected by ethidium bromide staining (lower panels). IHF is a heterodimer consisting of IHF $\alpha$ and $\mathrm{IHF} \beta$, and thus both ihfA and ihfB mutants were analysed.

On the other hand, a marked increase in $\operatorname{csg} D$ mRNA level was observed for mutants lacking CpxR and H-NS, particularly in the stationary phase (Fig. 1b, lanes 3 and 7), indicating that $\mathrm{CpxR}$ and $\mathrm{H}-\mathrm{NS}$ are the negative regulators of the $\operatorname{csg} D$ promoter. Activation of the Cpx signalling pathway in response to surface interactions such as adhesion requires the outer-membrane protein NlpE (Snyder et al., 1995; Otto \& Silhavy, 2002). When NlpE was overexpressed, transcription of $c p x P$, one of the known targets of CpxR, was indeed activated, but transcription of $\operatorname{csg} D$ was markedly reduced (Fig. 2a, lanes 1 and 2). In the absence of CpxR, NlpE overexpression did not lead to reduction of $\operatorname{csg} D$ transcription (Fig. 2a, lanes 3 and 4). Taking these results together we concluded that CpxR plays a negative role in $\operatorname{csgD}$ ranscription. Nucleoid protein H-NS is known as a general silencer of transcription in E. coli (reviewed by Ishihama, 2009). In the absence of H-NS, the level of $c s g D$ 


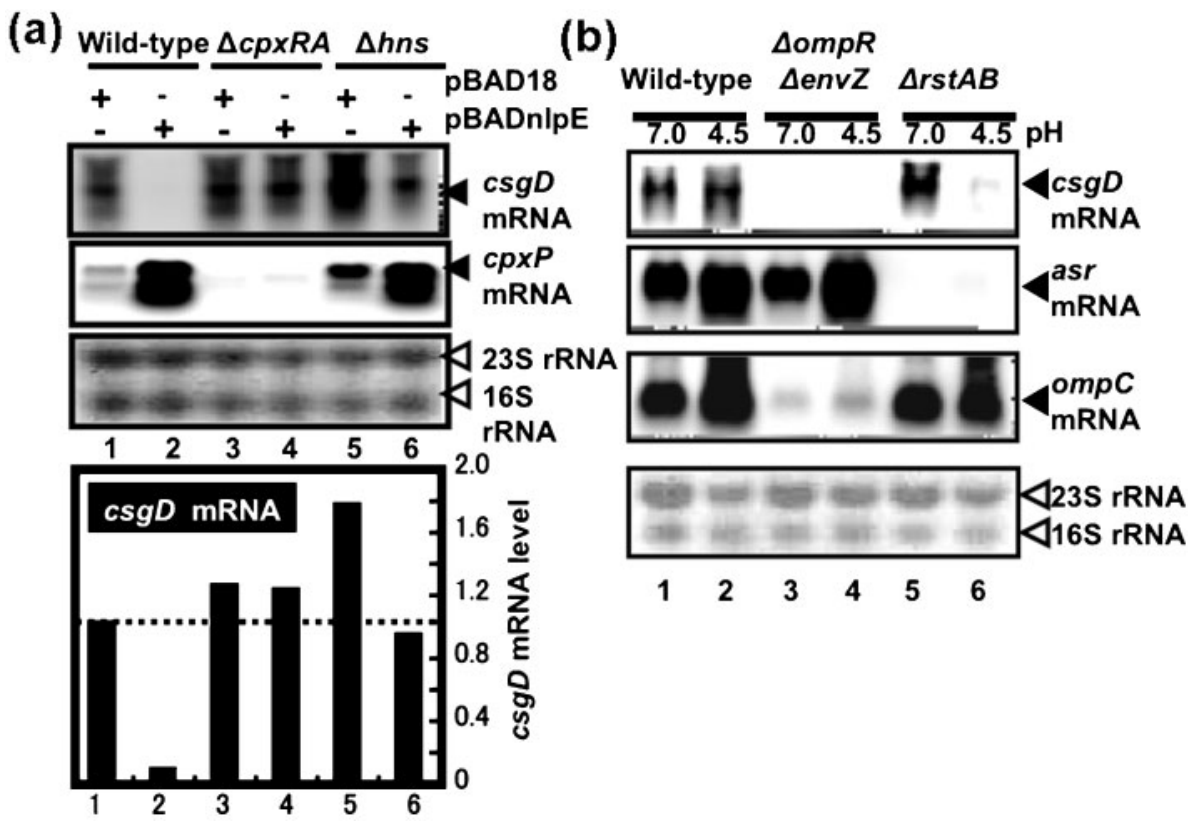

Fig. 2. Expression level of $c s g D$ mRNA. (a) E. coli wild-type K-12 BW25113 (lanes 1 and 2), cpxRA mutant (lanes 3 and 4 ) and $h n s$ mutant (lanes 5 and 6) containing either control plasmid pBAD18 (lanes 1, 3, and 5) or NlpE expression plasmid pBADnlpE (lanes 2, 4, and 6) were grown in LB medium at $28^{\circ} \mathrm{C}$ for $12 \mathrm{~h}$ in YESCA medium in the presence of $0.2 \%$ arabinose. Total RNA was isolated from each culture, fractionated by PAGE and subjected to Northern blotting. Both csg $D$ and cpxP RNA were detected with DIG-labelled $\operatorname{csg} D$ or $\operatorname{cpxP} 3^{\prime}$ probes (see Table 1) while rRNA was detected by ethidium bromide staining (upper panel). The band intensity was measured and normalized by $\operatorname{csg} D$ mRNA in wild-type BW25113(pBAD18) (lower panel). (b) Overnight cultures of E. coli wild-type BW25113 (lanes 1 and 2), ompR envZ double mutant (lanes 3 and 4 ) and $r s t A$ rst $B$ double mutant (lanes 5 and 6 ) were transferred into fresh YESCA medium at either pH 7.0 or $\mathrm{pH} 4.5$, and grown at $28{ }^{\circ} \mathrm{C}$ for $12 \mathrm{~h}$. Total RNA was subjected to Northern blot analysis as in (a).

mRNA significantly increased (Fig. 2a, lanes 1 and 5), indicating that $\mathrm{H}-\mathrm{NS}$ is a repressor of the $\operatorname{csg} D$ promoter. The reduction of $c s g D$ mRNA mediated by CpxR-NlpE was, however, observed in this hns knockout mutant (Fig. 2a, lanes 5 and 6).

In the $r s t A B$ mutant grown at $\mathrm{pH} 7.0$, the level of $\operatorname{csg} D$ mRNA increased slightly (Fig. 2b, lane 5) while overproduction of RstA resulted in significant reduction of $\operatorname{csg} D$ mRNA (Ogasawara et al., 2007a), these results together indicating a negative role of RstA in $\operatorname{csg} D$ transcription. In the absence of RstA, however, translation of $r p o S$ is enhanced (Sugiura et al., 2003) while overproduction of RstA induces degradation of RpoS in Salmonella (Cabeza et al., 2007). Thus the observed change in $\operatorname{csg} \mathrm{D}$ transcription at neutral $\mathrm{pH}$ might not be the direct consequence of the change in repressor RstA level but a result of the change of RpoS level. Previously we noticed that RstA is involved in asr activation for the acid stress response (Ogasawara et al., 2007a). We therefore examined the possible influence of acidic conditions on $\operatorname{csg} D$ transcription. In the wild-type strain, the level of $\operatorname{csg} D$ transcription was essentially the same between $\mathrm{pH} 7.0$ and pH 4.5 (Fig. 2b, lanes 1 and 2), in agreement with the published observation (Gerstel \& Romling, 2001). In contrast, however, $\operatorname{cs} g D$ mRNA was virtually undetectable in the $r s t A$ knockout mutant grown at $\mathrm{pH} 4.5$ (Fig. 2b, lanes 5 and 6). This finding supports the interpretation that RstA is required for $c s g D$ transcription at low $\mathrm{pH}$.

\section{Intracellular concentrations of transcription factors}

Growth-dependent change in the $\operatorname{csg} D$ promoter in wildtype E. coli, shown in Fig. 1(b), might be attributable to changes in the intracellular concentrations of transcription factors involved in the regulation of the $\operatorname{csg} D$ promoter. The intracellular level of the test transcription factors was therefore determined at various times of cell growth by using quantitative immunoblotting (Jishage et al., 1996; Maeda et al., 2000). In growing cells, the intracellular concentrations of two nucleoid proteins, IHF and H-NS, are similar and higher than those of the specific regulators, RstA, OmpR and CpxR (Fig. 3). Upon entry to the stationary phase, a 2.5- to 3-fold increase was observed for IHF, reaching a level of 25000-30000 molecules per cell (Fig. 3). In contrast, H-NS stayed constant at a level of approximately 10000 molecules per cell (Fig. 3). The levels of these two nucleoid proteins are in good agreement with our previous determination (Ishihama, 1993; Azam et al., 

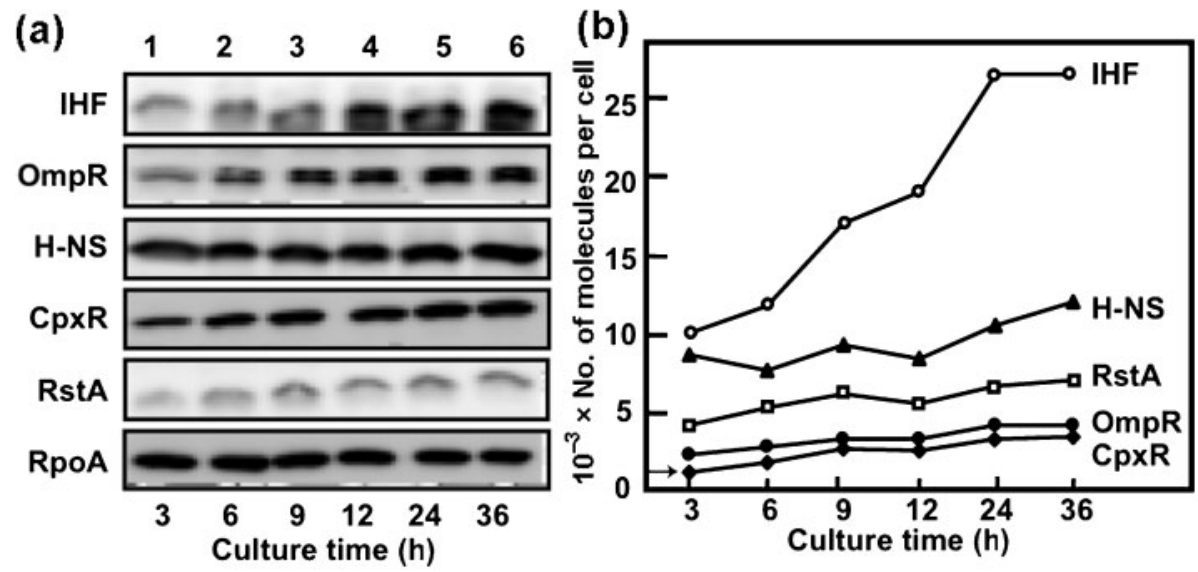

\begin{abstract}
Fig. 3. Intracellular concentrations of the test transcription factors. (a) Overnight culture of wild-type E. coli K-12 BW25113 was transferred into fresh YESCA medium and cultured at $28{ }^{\circ} \mathrm{C}$. At the times indicated, whole-cell lysates were prepared and subjected to quantitative Western blot analysis using antibodies against IHF, OmpR, H-NS, CpxR and RstA (upper panels), and anti-RpoA (bottom panel). (b) The intensity of immunoblot bands was measured with a LAS-4000 image analyser and IMAGE GAUGE (Fuji Film). Under the culture conditions, the intracellular concentration of RpoA was determined to be 5000 molecules per genome equivalent of DNA (Jishage et al., 1996; Maeda et al., 2000). The level of transcription factors was then determined based on the difference of immunostaining intensity between RpoA and test transcription factors. The relative level was calculated against the concentration (957 molecules per genome equivalent of DNA) of CpxR at $3 \mathrm{~h}$ (shown by an arrow).
\end{abstract}

1999). The enhancement of $\operatorname{csg} D$ transcription in the stationary phase might be due, at least in part, to the increase in the level of a positive factor IHF (see below for the competition between IHF and H-NS). Upon entry to the stationary phase, the levels of three specific regulators also increased slightly, but their relative ratio remained constant. The relative order, RstA $>0 \mathrm{mpR}>\mathrm{CpxR}$, was also unaltered from exponential to stationary phase (Fig. 3). Thus, except for the marked increase of IHF, the change in the intracellular concentrations of other transcription factors might not be the major cause of the activation of $\operatorname{csg} D$ promoter in the stationary phase.

\section{Interaction in vitro of five test transcription factors on the $\operatorname{csg} D$ promoter}

In order to examine the mechanisms of regulation of the $\operatorname{csg} D$ promoter by these five factors, we purified all five factors to near homogeneity and subjected them to the gel retardation assay using various DNA fragment probes covering the $\operatorname{csg} D$ promoter sequence. Among the five factors examined, the three response regulators, OmpR, RstA and CpxR, are organized in two-component systems, and are converted to active forms only when phosphorylated by the respective sensor kinases, EnvZ (Aiba et al., 1989; Yamamoto et al., 2005), RstB (Minagawa et al., 2003; Yamamoto et al., 2005) and CpxA (Raivio \& Silhavy, 1997; Yamamoto et al., 2005), respectively. Thus, the DNAbinding activity of OmpR, RstA and CpxR was examined in the presence of acetyl phosphate for phosphorylation in vitro (note that phosphorylated forms are shown as OmpRp, RstAp and CpxRp in the respective figures).
All five transcription factors, CpxR, OmpR, RstA, IHF and $\mathrm{H}-\mathrm{NS}$, formed binary DNA complexes in vitro in the absence of other factors (Fig. 4). The two nucleoid proteins, IHF and $\mathrm{H}-\mathrm{NS}$, formed more than two complex bands on PAGE, indicating the presence of more than two binding sites on the respective probes. The binding affinity of these five factors to the $\operatorname{csg} D$ promoter could be estimated based on the proteindose-dependent disappearance pattern of probe DNA. The apparent affinity for the $c s g D$ promoter was found to be high for IHF and CpxR, followed by OmpR, H-NS and RstA (Fig. 4). Since both IHF and H-NS bind at multiple sites on the $\operatorname{csg} D$ promoter, the actual affinity per single binding site might be lower for these nucleoid proteins as described in our previous report (Azam \& Ishihama, 1999).

\section{Transcription-factor-binding sequences on the csgD promoter}

To get insight into the mechanism by which the $\operatorname{csg} D$ promoter is regulated by these five transcription factors, we next determined the site(s) of recognition and binding in vitro by each purified protein. For identification of the binding sequences by all five transcription factors, DNase I footprinting mapping was performed using the respective purified proteins and the $\operatorname{csg} D$ promoter DNA fragment (see Fig. 5 for the gel patterns and Fig. 6 for the protected sequences). A single unique protection sequence was identified for OmpR and RstA, while two sites were identified with IHF. Interestingly, all five transcription factors bind to the same region between -61 and -43 , hereafter designated hot-spot II. In addition, three factors, IHF, CpxR and H-NS, bind to the same upstream region 


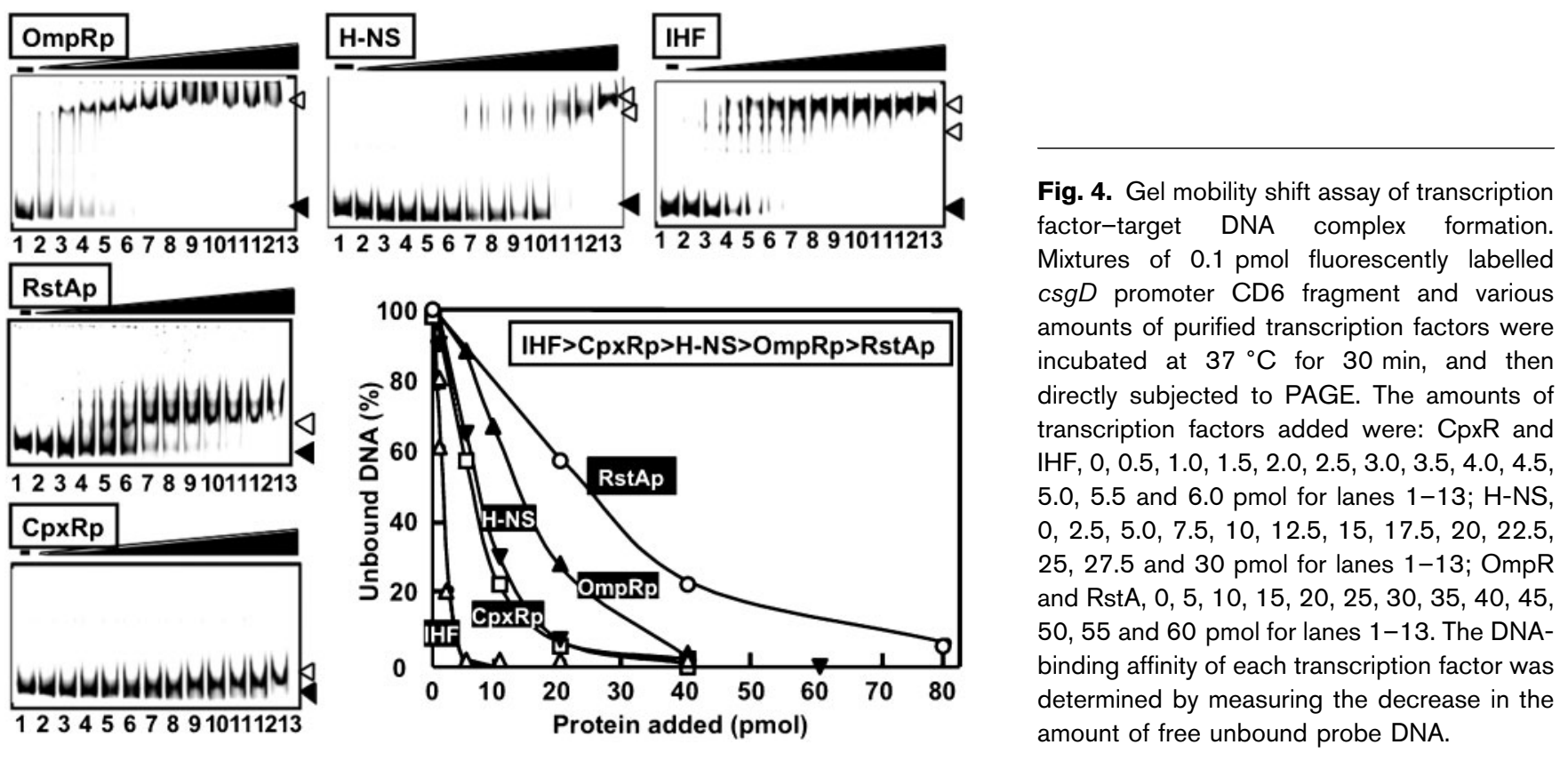

between -188 and -159 , designated hot-spot I. Interplay between transcription factors in binding to these two hotspots should influence the level of $\operatorname{csg} D$ transcription.

OmpR, the response regulator of the EnvZ-OmpR twocomponent system, which senses the environmental osmolarity, was found to bind a 24 bp sequence ( -62 to -39) (Fig. 5) including a direct repeat sequence of (-59)TTACATTTAgTTACATGTT(-40) (Fig. 6), which agrees with the OmpR box (Harlocker et al., 1995; Pratt \& Silhavy, 1995; Ishihama, 2010). The location of the OmpRbinding site on the $\operatorname{csg} D$ promoter is consistent with the determinations by other laboratories (Vidal et al., 1998; Jubelin et al., 2005). After genomic SELEX screening, we found that the RstBA two-component system is under the control of the $\mathrm{Mg}(\mathrm{II})$-sensing PhoQP two-component system (Ogasawara et al., 2007a). Among the regulation targets of RstA identified by genomic SELEX, we found the

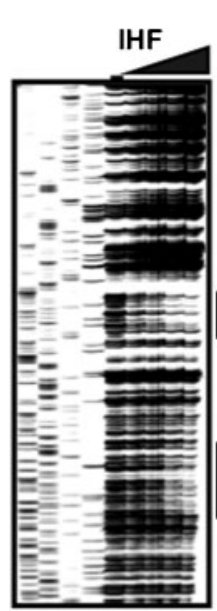

ATGC12345
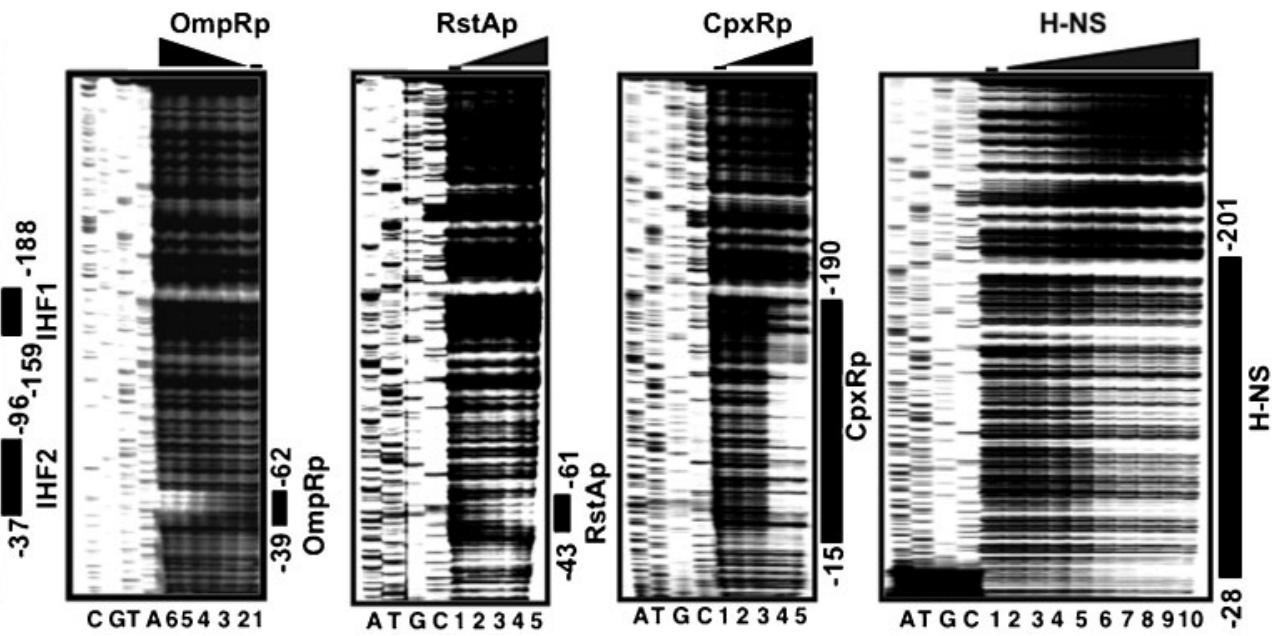

Fig. 5. DNase I footprinting of transcription-factor-binding sites on the $\operatorname{csg} D$ promoter. The fluorescently labelled $\operatorname{csg} D$ promoter segment $(1.0 \mathrm{pmol})$ was incubated in the absence (lane 1) or presence of increasing concentrations of purified transcription factors (lanes 2-5), and then subjected to DNase I footprinting assays. Lanes A, T, G and C represent the sequence ladders. The amounts of proteins used were (from lane 2 to 5): 1.25, 2.5, 5 and 10 pmol for IHF; 2.5, 5, 10 and 20 pmol for CpxR; 5, 10, 20 and 40 pmol for OmpR and H-NS in the absence (H-NS and IHF) or presence (CpxR, OmpR and RstA) of acetyl phosphate (10 mM). Bold lines on the right indicate the transcription-factor-binding sequences as detected by the protection pattern from DNase I treatment. The nucleotide numbers represent the distances from the transcription initiation site $\mathrm{P} 1$. 


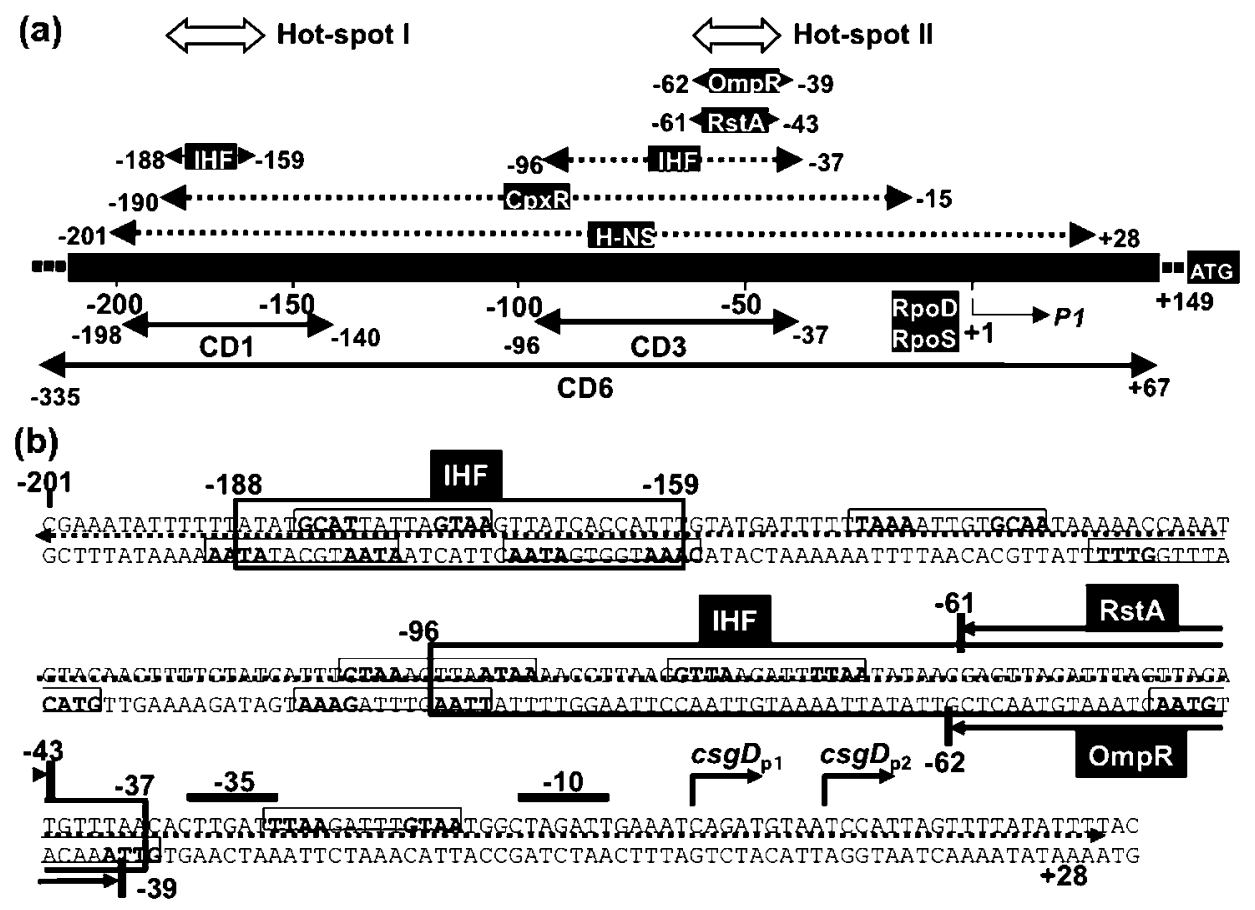

Fig. 6. (a) Location of the transcription-factor-binding sites on the $\operatorname{csg} D$ promoter. The binding sites of OmpR, RstA, CpxR, IHF and $\mathrm{H}-\mathrm{NS}$ were identified by DNase I footprinting assays (for gel patterns see Fig. 5 ) and are shown along the csg $D$ promoter sequence. Multiple binding sites were identified for IHF, CpxR and H-NS. The promoter-proximal site is designated site 1 for these factors. $P 1$ represents the transcription initiation site P1 (Hammar et al., 1995). The transcription-factor-binding sites are shown by dotted lines above the csgD promoter DNA bar. The numbers at the ends of each line represent the distance from the $\mathrm{P} 1$ transcription start site. CD1, CD3 and CD6 represent the sequences used for preparation of the DNA probes for the competition assay in DNA binding among the transcription factors. (b) Nucleotide sequence of the csgD promoter region. The binding sites of IHF, OmpR, RstA and CpxR are indicated along the csgD promoter sequence while the H-NS-binding sequence is shown by a dotted line between the duplex sequences. The sequences boxed with thin lines, including bold nucleotides, indicate the consensus sequence of the CpxR box [GTAA $\left.\left(N_{5}\right) G T A A\right]$. The numbers at the ends of each line represent the distance from the $\mathrm{P} 1$ transcription start site. p2 represents the p2 promoter (Ogasawara et al., 2007a)

consensus sequence of TACATNTNGTTACA as a common sequence recognized by RstA (Ishihama, 2010). This RstAbox-like sequence $(-56)$ TACATTAGTTACA $(-44)$ is present within the region protected by RstA $(-61$ to -43$)$ (Fig. 6). CpxR, the response regulator of the CpxAR twocomponent system, which monitors denaturation of membrane proteins, binds to the consensus CpxR box consisting of a direct repeat sequence of GTAA $\left(\mathrm{N}_{5-7}\right)$ GTAA (Pogliano et al., 1997; Yamamoto \& Ishihama, 2006; Ishihama, 2010). On the $\operatorname{csg} D$ promoter, CpxR was found to bind over a long sequence $(-190$ to -15$)$ including the CpxR-like sequences (Fig. 6). This CpxR-binding sequence mostly overlaps the reported CpxR sites $(-107$ to +9$)$ (Jubelin et al., 2005).

IHF is one of the major nucleoid architectural proteins (Azam et al., 1999; Ishihama, 1999, 2009) but it also functions as a global regulator of transcription when it binds near promoters (for a review see Ishihama, 2009). IHF has been indicated to be involved in regulation of the $\operatorname{csg} D$ promoter (Gerstel et al., 2003, 2006). In fact, we identified two IHF-binding sites, one between -188 and -159 (IHF-1) and another between -96 and -37 (IHF-2), on the $\operatorname{csg} D$ promoter (Fig. 6; for the DNase footprinting pattern see Fig. 5). The promoter-proximal IHF-2 was not identified in Salmonella (Gerstel et al., 2003). The upstream IHF-1 overlaps with the H-NS- and CpxR-binding sites, altogether forming the transcription-factor-binding hotspot I, while the downstream IHF-2 overlaps with the binding sites of all the other four factors, OmpR, RstA, CpxR and N-NS, forming hot-spot II (Fig. 6).

H-NS prefers curved DNA for binding and often functions as a general silencer of gene transcription by binding near the promoter of target genes (for reviews see Ishihama, 1999, 2009; Dorman, 2004). On the $\operatorname{csg} D$ promoter, H-NS protects a wide region $(-201$ to +28$)$ including AT-rich sequences (Fig. 6), implying that the $\operatorname{csg} D$ promoter is a silencing target of H-NS.

\section{Interplay between transcription factors in binding to the csgD promoter}

All five transcription factors were found to bind within a narrow region of 229 bp in length between -201 and +28 
of the $\operatorname{csg} D$ promoter (Fig. 6). The contact sites of these five factors overlap in various combinations within this $229 \mathrm{bp}$ sequence. In particular, three factors bind at the upstream hot-spot I between -188 and -159 and five factors at the downstream hot-spot II between -61 and -43 . Thus, interplay between these factors, each monitoring one specific environmental factor or condition, should influence $\operatorname{csg} D$ expression, ultimately leading to control biofilm formation. As an initial attempt to elucidate this, we analysed pair-wise interplay between the five transcription factors. In addition to the competition between positive and negative factors, we found unexpected cooperation between two negative factors, CpxR and H-NS, and between two pairs of positive factors, OmpR and IHF, and RstA and IHF.

Competition between positive and negative factors. The two nucleoid proteins, IHF and H-NS, exhibited opposite effects on transcription from the $c s g D$ promoter. As noted above, IHF acts as a positive regulator while H-NS is a potent repressor. IHF binds at two regions, one between -188 and -159 (IHF-1) and another between -96 and -37 (IHF-2), including the transcription-factor-binding hot-spots I and II, respectively. Since the IHF-2 region is almost twice the length of IHF-1, two molecules of IHF should bind on the IHF-2 site. On the other hand, H-NS binds at a long sequence, possibly including four sites, covering almost the entire $\operatorname{csg} D$ promoter from -201 to +28 (see Fig. 6). We thus examined possible competition between the two nucleoid proteins using two DNA fragment probes, CD1 ( -198 to -140 ; including hot-spot I) and CD3
( -96 to -37 ; including hot-spot II), covering the upstream (IHF-1) and downstream (IHF-2) IHF-binding site, respectively (Fig. 7c). [Note that in Salmonella, only one IHF-binding site exists on the $\operatorname{csg} D$ promoter (Gerstel et al., 2003).]

When the amount of H-NS added was increased in the presence of a saturating amount of IHF, H-NS was able to bind by replacing IHF sites (Fig. 7a, b, lanes 8-10). On the other hand, the addition of increasing amounts of IHF in the presence of a high concentration of H-NS to saturate the $\mathrm{CD} 1$ and $\mathrm{CD} 3$ probes did not change the gel pattern (Fig. 7a, b, lanes 11-13). These results indicate that the two nucleoid proteins, IHF and H-NS, compete with each other for binding to the respective target sequences, and in the presence of high concentrations of both proteins, only the $\mathrm{H}$-NS complexes are formed because of the higher affinity of H-NS than IHF. However, when the 400 bp probe CD6, including both the IHF-1 and the IHF-2 sites, was used, IHF-H-NS-DNA ternary complexes were detected (data not shown), implying that IHF was not ejected even in the presence of high concentrations of H-NS. The simultaneous binding of two molecules of IHF to both the IHF-1 and the IHF-2 sites must strengthen their DNA-binding affinity, possibly through IHF-IHF interaction, thereby leading to resistance against competition from H-NS. This finding suggests that the intracellular concentrations of IHF and H-NS influence $\operatorname{csg} D$ transcription.

In the exponential growth phase, the intracellular concentration of H-NS and IHF is similar, but upon entry into
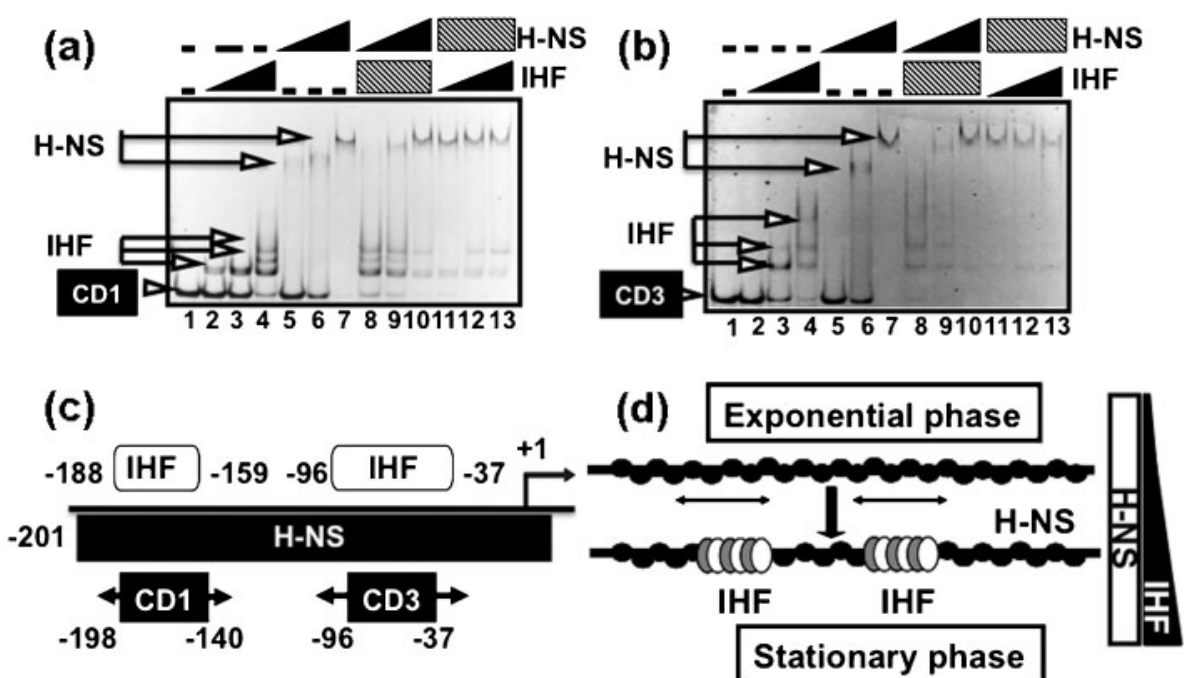

Fig. 7. Competition between IHF and H-NS in DNA binding. (a) The gel shift assay was carried out using the two nucleoid proteins, IHF and H-NS, with FITC-labelled CD1 probe DNA. Proteins used were: IHF alone (lane 1, 0; lanes 2-4, 0.625, 1.25 and $2.5 \mathrm{pmol}$ ); H-NS alone (lanes 5-7, 10, 20 and 40 pmol); H-NS (lanes 8-10, 10, 20 and 40 pmol) plus IHF (2.5 pmol); and $\mathrm{H}-\mathrm{NS}$ (40 pmol) plus IHF (lanes 11-13, 0.625, 1.25 and 2.5 pmol). (b) The gel shift assay was carried out using IHF and H-NS with FITC-labelled CD3 probe DNA. Proteins used were as in (a). (c) Location of the IHF- and H-NS-binding sites along the $\operatorname{csg} \mathrm{D}$ promoter and the probes used for competition assay. (d) Model of growth-phase-dependent competition between $\mathrm{H}-\mathrm{NS}$ and IHF on the $\operatorname{csg} D$ promoter. 
stationary phase, the IHF level increases 2.5-3-fold while the H-NS level stays almost constant (see Fig. 3). As a result, the increased amount of IHF bound on the $\operatorname{csg} D$ promoter should lead to cancellation of the H-NSmediated silencing of $\operatorname{csg} D$ in stationary phase (Fig. $7 \mathrm{~d}$ ).

\section{Cooperation between the two negative factors CpxR} and H-NS. $c s g D$ mRNA markedly increased in a mutant lacking CpxR (see Fig. 1), in agreement with its negative regulator model (Jubelin et al., 2005). Since both CpxR and H-NS bind to wide and overlapping regions, -190 and -15 for CpxR and -201 and +28 for H-NS, we used the long probe CD6 ( -335 to +67 ; see Fig. 6$)$ for the gel shift assay. Both CpxR and H-NS alone formed multiple CD6 complexes, in agreement with the presence of multiple binding sites for both factors (Fig. 8a, lanes 2-12). In the simultaneous presence of both CpxR and H-NS, the DNA complexes were supershifted (Fig. 8a, lanes 13-19), indicating that both these factors are able to bind simultaneously on the CD6 probe even though the binding sites mostly overlap. This finding implies cooperative repression of the $\operatorname{csg} D$ promoter by the two negative factors CpxR and H-NS.

Cooperation between the two positive factors OmpR and IHF. The binding site of the positive regulator OmpR
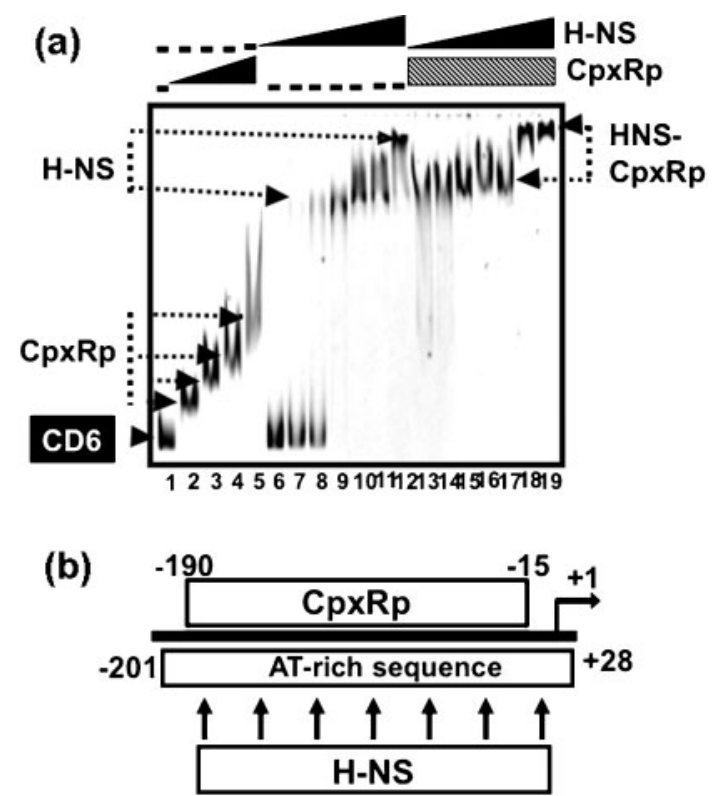

Fig. 8. Cooperative binding of the two repressors $\mathrm{CpxR}$ and $\mathrm{H}-$ NS to the $\operatorname{csg} D$ promoter. (a) The gel shift assay was carried out using CpxR and H-NS with FITC-labelled CD6 probe DNA in the presence of acetyl phosphate $(10 \mathrm{mM})$. Proteins used were: CpxR alone (lanes 1-5, 0, 5, 10, 15 and 20 pmol); H-NS alone (lanes 6$12,10,15,20,25,30,35$ and 40 pmol); H-NS (lanes $13-19$ as in lanes 6-12) plus CpxR (20 pmol). (b) Model of cooperation between CpxR and H-NS in binding to the $\operatorname{csg} D$ promoter. Both CpxR and $\mathrm{H}-\mathrm{NS}$ are able to bind to the $\operatorname{csg} D$ promoter simultaneously. on the $\operatorname{csg} D$ promoter $(-62$ to -39$)$ within hot-spot II overlaps with the promoter-proximal IHF-2 site ( -96 to -37). When CD6 was used as a probe, both OmpR and IHF bound to the same probe (Fig. 9b), as expected from the map of binding sites (Fig. 9a). However, even when the gel shift assay was performed using the shorter probe $\mathrm{CD} 3$, the complex band was again supershifted to highmolecular-mass complexes (Fig. 9c), indicating that both OmpR and IHF were capable of binding simultaneously to

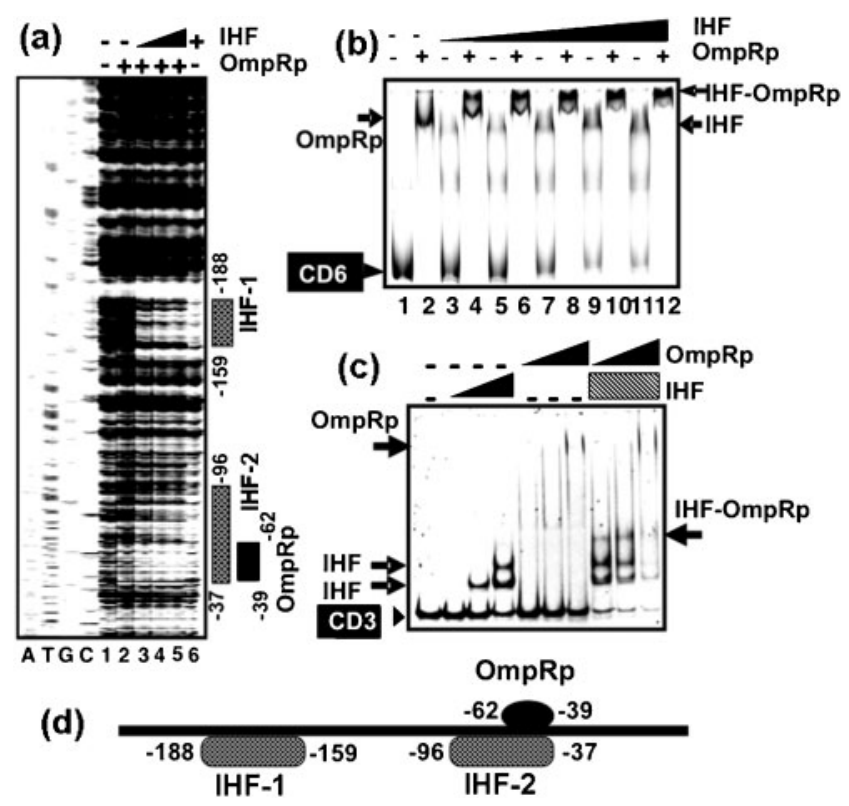

Fig. 9. Cooperative binding of the two activators IHF and OmpR to the $\operatorname{csg} D$ promoter. (a) DNase I footprinting analysis of the $\operatorname{csg} D$ promoter by IHF and OmpRp. Fluorescently labelled DNA probe of the $\operatorname{csg} D$ promoter $\mathrm{CD} 1$ fragment $(1 \mathrm{pmol})$ was incubated with increasing concentrations of purified IHF (lanes 1 and 2, 0 pmol; lane 3, $2.5 \mathrm{pmol}$, lane 4, $5.0 \mathrm{pmol}$; lanes 5 and 6, $10 \mathrm{pmol}$ ) in the absence (lane 1,6) or presence (lanes 2-5) of OmpR (80 pmol) and subjected to DNase I footprinting assays as described in Methods. The bars on the right indicate the IHF- and OmpRpbinding sequences. The nucleotide numbers represent the distance from the transcription initiation site P1. (b) Gel shift assay in the presence of both IHF and OmpR. Fluorescently labelled csgD CD6 probe was incubated at $37^{\circ} \mathrm{C}$ for $10 \mathrm{~min}$ with IHF (lanes 1 and 2, 0 pmol; lanes 3 and 4, 1.0 pmol; lanes 5 and 6, $1.5 \mathrm{pmol}$; lanes 7 and 8, 2.0 pmol; lanes 9 and 10, 2.5 pmol; lanes 11 and 12, $3.0 \mathrm{pmol}$ ), and then $30 \mathrm{pmol}$ OmpR (lane 2, 4, 6, 8, 10, 12) was added together with $10 \mathrm{mM}$ acetyl phosphate and incubated at $37{ }^{\circ} \mathrm{C}$ for $20 \mathrm{~min}$. The protein/DNA mixtures were directly subjected to PAGE. (c) Gel shift assay in the presence of both IHP and OmpR. FITC-labelled CD3 probe DNA was incubated with IHF and/or OmpR at $37{ }^{\circ} \mathrm{C}$ for $10 \mathrm{~min}$. Proteins used were: IHF alone (lanes 1-4, 0, 0.625, 1.25 and $2.5 \mathrm{pmol}$ ); OmpR alone (lanes 5-7, 10, 20 and 40 pmol); OmpR (lanes 8-10 as in lanes 5-7) plus IHF (2.5 pmol). (d) Model of cooperation between OmpR and IHF in binding to the $\operatorname{csg} D$ promoter. Both OmpR and IHF are able to bind to the IHF-2 site simultaneously. 
the short CD3 probe (Fig. 9c) even though the OmpRbinding site and the downstream IHF-binding site IHF-2 completely overlap on CD3. Since there are two IHFbinding sites within IHF-2, the CD3 probe formed multiple species of OmpR-IHF-CD3 complex, e.g. IHF-OmpRCD3 and IHF-IHF-OmpR-CD3, should be formed in the simultaneous presence of two factors, thereby giving a broad distribution of complexes.

\section{Cooperation between the two positive factors RstA and} IHF. The binding site of the positive regulator RstA on the $\operatorname{csg} D$ promoter ( -61 to -43$)$ also overlaps with the promoter-proximal IHF-2 (-96 to -37 ) (see Fig. 6). When CD6 was used as a probe, both RstA and IHF bound to the probe (Fig. 10a) as expected from the map of binding sites. When the gel shift assay was performed using the shorter CD3 probe, the complex band was again supershifted to high-molecular-mass complexes (Fig. 10b), indicating that both RstA and IHF are capable of binding simultaneously to this short probe (Fig. 10c), forming
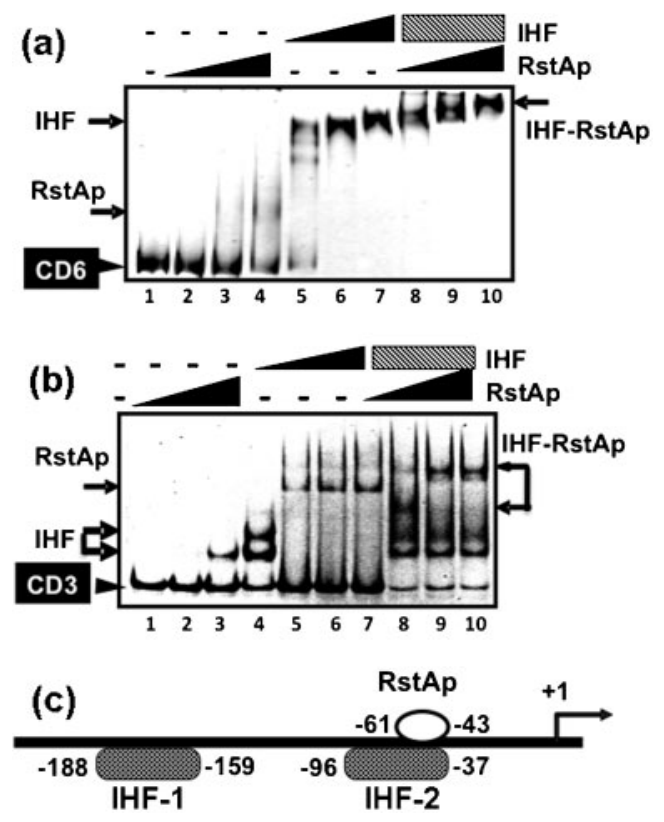

Fig. 10. Cooperative binding of the two activators RstA and IHF to the $\operatorname{csg} D$ promoter. (a) The gel shift assay was carried out using RstA and IHF with FITC-labelled CD6 probe DNA in the presence of acetyl phosphate $(10 \mathrm{mM})$. Proteins used were: RstA alone (lanes 1-4, 0, 5, 10 and 20 pmol); IHF alone (lanes 5-7, 0.625, 1.25 and 2.5 pmol); RstA (lanes 8-10 as in lanes 2-4) plus IHF (2.5 pmol). (b) The gel shift assay was carried out using RstA and IHF with FITC-labelled CD3 probe DNA in the presence of acetyl phosphate $(10 \mathrm{mM})$. Proteins used were: IHF alone (lanes 2-4, $0.625,1.25$ and 2.5 pmol); RstAp alone (lanes 5-7, 10, 20 and 40 pmol); RstA (lanes 8-10 as in lanes 5-7) plus IHF (2.5 pmol). (c) Model of cooperation between RstA and IHF in binding to the $\operatorname{csg} D$ promoter. Both RstA and IHF are able to bind to the IHF-2 site simultaneously.
IHF-RstA-CD3 and IHF-IHF-RstA-CD3 complexes as in the case of OmpR-IHF interplay (see Fig. 9).

\section{Multi-factor promoters in prokaryotes}

Biofilm is formed under various stress conditions. Reflecting such situations in nature, the promoter for the master regulator $\mathrm{CsgD}$ is under the control of a number of transcription factors. Here we identified that five regulatory proteins (CpxR, OmpR, RstA, IHF and H-NS) bind within a narrow region of about 229 bp along the $\operatorname{csg} D$ promoter (see Fig. 6). Northern blot analysis of $\operatorname{csg} D$ mRNA indicated that these factors could be classified into two groups: three positive factors (OmpR, IHF and RstA) and two negative factors (CpxR and H-NS) (see Fig. 1). Of the three positive factors, RstA functions as a positive factor of $\operatorname{csg} D$ transcription only under acidic conditions (see Fig. 3). Interestingly, there are two hot-spots for regulator binding: three factors (IHF, CpxR and H-NS) bind at hot-spot I between -188 and -159 , and all five factors bind at hot-spot II between -61 and -43 (see Fig. 6a). The simultaneous binding of multiple regulators on the $\operatorname{csg} D$ promoter presumably through protein-protein interaction should increase the binding affinity of each factor to the respective target sequence and in addition, should influence direct protein-protein contact with RNA polymerase $\alpha$ CTD or $\sigma$ CTD (Ishihama, 1993; Busby \& Ebright, 1999) for amplification of regulatory functions. Judging from the number of transcription factors involved in regulation, the $\operatorname{csg} D$ promoter is the most complex promoter so far analysed in E. coli (Ishihama, 2010).

All the nucleoid proteins are bifunctional, playing both architectural and regulatory roles (Ishihama, 2009). Within the $200 \mathrm{bp}$ sequence upstream from the $\operatorname{csg} D$ promoter, IHF binds at least at two sites (see Fig. 6). The functional IHF protomer is a heterodimer composed of IHF $\alpha$ (encoded by ihfA) and IHF $\beta$ (encoded by ihfB), each being interwound to form a compact body. IHF recognizes specific sequences for binding and facilitates DNA bending with the bend angle of about $160^{\circ}$ as analysed by crystallography (Rice et al., 1996), thereby affecting transcription. The binding of IHF to the $c s g D$ promoterproximal site IHF-2 should activate its transcription through protein-protein contacts with either $\alpha$ CTD or $\sigma$ CTD (Ishihama, 1993). IHF also binds at promoter-distal site IHF-1 (see Fig. 6). The activation of the $\operatorname{csg} D$ promoter by IHF associated with site IHF-1 might be attributable to a conformational change of the upstream segment of the $\operatorname{csg} D$ promoter, for instance through protein-protein interaction between site-1- and site-2-associated IHF molecules.

On the other hand, H-NS is a global repressor of transcription, sometimes called a silencer (Dorman, 2004; Ishihama, 2009). H-NS employs a mechanism of DNA recognition different from that of IHF. One H-NS dimer binds to each 15-20 bp (Amit et al., 2003) and bridges adjacent tracts of DNA, resulting in lateral condensation of 
large regions and formation of large globular structures (Dame et al., 2005). The effect of H-NS on gene expression is direct, being mediated by binding of $\mathrm{H}-\mathrm{NS}$ and changing the DNA topology of the promoter region, functioning as a transcription silencer through interference with the formation of RNA polymerase-promoter complex (Navarre et al., 2006). H-NS binds to the AT-rich sequence within the $200 \mathrm{bp}$ sequence upstream from the $c s g D$ promoter, and interferes with the binding of RNA polymerase (data not shown). The level of $\operatorname{csg} D$ silencing may be related to the number and location of H-NS binding sites among the four potential binding sites along the $\operatorname{csg} D$ promoter. Thus, the silencing of $\operatorname{csg} D$ by H-NS should be reduced in stationary phase because of the increase in IHF level (see Fig. 2).

\section{Conclusions}

More than 10 transcription factors are involved in regulation of the $\operatorname{csg} D$ promoter of the master regulator operon for biofilm formation. Judging from the number of transcription factors involved in regulation, the $\operatorname{csg} D$ promoter can be categorized as one of the most complex E. coli promoters. Each transcription factor monitors a specific factor or condition in nature for the control of biofilm formation. Based on the in vitro binding assays, we propose not only competition between the positive and negative factors but also cooperation within the positive and negative factor groups. Detailed understanding of the $\operatorname{csg} D$ promoter regulation system should provide a better understanding of the genome regulation for survival of $E$. coli in nature.

\section{ACKNOWLEDGEMENTS}

This work was supported by a Grant-in-Aid for Scientific Research on Priority Area System Cell Engineering by Multi-Scale Manipulation (17076016) to A.I. and Grants-in-Aid for Scientific Research (A) (21241047) and (B) (18310133) to A.I. and Grant-in-Aid for JSPS Fellows (218850) to H. O. from the Ministry of Education, Culture, Sports, Science and Technology of Japan. We also aknowledge the support from Project of Micro-Nano Technology Research Center of Hosei University. H.O. is a recipient of a JSPS Post-doctoral Fellowship.

\section{REFERENCES}

Aiba, H., Nakasai, F., Mizushima, S. \& Mizuno, T. (1989). Phosphorylaton of a bacterial activator protein, OmpR, by a protein kinase, EnvZ, results in stimulation of its DNA-binding ability. J Biochem 106, 5-7.

Amit, R., Oppenheim, A. B. \& Stavans, J. (2003). Increased bending rigidity of single DNA molecules by H-NS, a temperature and osmolarity sensor. Biophys J 84, 2467-2473.

Arnqvist, A., Olsen, A. \& Normark, S. (1994). Sigma S-dependent growth-phase induction of the $\operatorname{csg} B A$ promoter in Escherichia coli can be achieved in vivo by sigma 70 in the absence of the nucleoidassociated protein H-NS. Mol Microbiol 13, 1021-1032.

Azam, T. A. \& Ishihama, A. (1999). Twelve species of DNA-binding protein from Escherichia coli: sequence recognition specificity and DNA binding affinity. J Biol Chem 274, 33105-33113.
Azam, T. A., Iwata, A., Nishimura, A., Ueda, S. \& Ishihama, A. (1999). Growth phase-dependent variation in the protein composition of Escherichia coli nucleoid. J Bacteriol 181, 6361-6370.

Barnhart, M. M. \& Chapman, M. R. (2006). Curli biogenesis and function. Annu Rev Microbiol 60, 131-147.

Beloin, C., Valle, J., Latour-Lambert, P., Faure, P., Kzreminski, J., Balestriono, D., Haagensen, J. A., Molin, S., Prensier, G. \& other authors (2004). Global impact of mature biofilm lifestyle on Escherichia coli K-12 gene expression. Mol Microbiol 51, 659-674.

Bian, Z., Brauner, A., Li, Y. \& Normark, S. (2000). Expression of and cytokine activation by Escherichia coli curli fibers in human sepsis. $J$ Infect Dis 181, 602-612.

Bougdour, A. \& Gottesman, S. (2007). ppGpp regulation of RpoS degradation via anti-adaptor IraP. Proc Natl Acad Sci U S A 104, 12896-12901.

Bougdour, A., Lelong, C. \& Geiselmann, J. (2004). Crl, a low temperature-induced protein in Escherichia coli that binds directly to the stationary phase sigma subunit of RNA polymerase. J Biol Chem 279, 19540-19550.

Brombacher, E., Dorel, C., Zehnder, A. J. \& Landini, P. (2003). The curli biosynthesis regulator CsgD co-ordinates the expression of both positive and negative determinants for biofilm formation in Escherichia coli. Microbiology 149, 2847-2857.

Brombacher, E., Baratto, A., Dorel, C. \& Landini, P. (2006). Gene expression regulation by the curli activator CsgD protein: modulation of cellulose biosynthesis and control of negative determinants for microbial adhesion. J Bacteriol 188, 2027-2037.

Brown, P. K., Dozois, C. M., Nickerson, C. A., Zupardo, A., Terlonge, J. \& Curtiss, R., III (2001). MlrA, a novel regulator curli (AgF) and exracellular matrix synthesis by Escherichia coli and Salmonella enterica serovar Typhimurium. Mol Microbiol 41, 349-363.

Busby, S. \& Ebright, R. (1999). Transcription activation by catabolite activator protein (CAP). J Mol Biol 293, 199-213.

Cabeza, M. L., Aguirre, A., Soncini, F. C. \& Vescovi, E. G. (2007). Induction of RpoS degradation by the two-component system regulator RstA in Salmonella enterica. J Bacteriol 189, 7335-7342.

Chapman, M. R., Robinson, L. S., Pinkner, J. S., Roth, R., Heuser, J., Hammar, M., Normark, S. \& Hultgren, S. J. (2002). Role of Escherichia coli curli operons in directing amyloid fiber formation. Science 295, 851-855.

Chirwa, N. T. \& Herrington, M. B. (2003). CsgD, a regulator of curli and cellulose synthesis, also regulates serine hydroxymethyltransferase synthesis in Escherichia coli K-12. Microbiology 149, 525-535.

Claret, L. \& Hughes, C. (2000). Functions of the subunits in the $\mathrm{FlhD}_{2} \mathrm{C}_{2}$ transcriptional master regulator of bacterial flagellum biogenesis and swarming. $J$ Mol Biol 303, 467-478.

Cookson, A. L., Cooley, W. A. \& Woodard, W. J. (2002). The role of type 1 and curli fimbriae of Shiga toxin-producing Escherichia coli in adherence to abiotic surfaces. Int J Med Microbiol 292, 195-205.

Dame, R. T., Luijsterburg, M. S., Krin, E., Bertin, P. N., Wagner, R. \& Wuite, G. J. L. (2005). DNA bridging: a property shared among H-NSlike proteins. J Bacteriol 187, 1845-1848.

Dorman, C. J. (2004). H-NS: a universal regulator for a dynamic genome. Nat Rev Microbiol 2, 391-400.

Ferrieres, L. \& Clarke, D. J. (2003). The RcsC sensor kinase is required for normal biofilm formation in Escherichia coli K-12 and controls the expression of a regulon in response to growth on a solid surface. $\mathrm{Mol}$ Microbiol 50, 1665-1682.

Gerstel, U. \& Romling, U. (2001). Oxygen tension and nutrient starvation are major signals that regulate $a g f D$ promoter activity and 
expression of the multicellular morphotype in Salmonella typhimurium. Environ Microbiol 3, 638-648.

Gerstel, U., Park, C. \& Romling, U. (2003). Complex regulation of $\operatorname{csg} D$ promoter activity by global regulatory proteins. Mol Microbiol 49, 639-654.

Gerstel, U., Kolb, A. \& Romling, U. (2006). Regulatory components at the $\operatorname{csg} D$ promoter: additional roles for OmpR and integration host factor and role of the $5^{\prime}$ untranslated region. FEMS Microbiol Lett 261, 109-117.

Gophna, U., Barlev, M., Seijffers, R., Oelschlager, T. A., Hacker, J. \& Ron, E. Z. (2001). Curli fibers mediate internalization of Escherichia coli by eukaryotic cells. Infect Immun 69, 2659-2665.

Gualdi, L., Tagliabue, L. \& Landini, P. (2007). Biofilm formation-gene expression relay system in Escherichia coli: modulation of sigma Sdependent gene expression by the $\mathrm{CsgD}$ regulatory protein via sigma S protein stabilization. J Bacteriol 189, 8034-8043.

Hammar, M., Arnqvist, A., Bian, Z., Olsen, A. \& Normark, S. (1995). Expression of two csg operons is required for production of fibronectin- and congo red-binding curli polymers in Escherichia coli K-12. Mol Microbiol 18, 661-670.

Harlocker, S. L., Bergstrom, L. \& Inouye, M. (1995). Tandem binding of six OmpR proteins to the $o m p F$ upstream regulatory sequence of Escherichia coli. J Biol Chem 270, 26849-26856.

Ishihama, A. (1993). Protein-protein communication within the transcription apparatus. J Bacteriol 175, 2483-2489.

Ishihama, A. (1999). Modulation of the nucleoid, the transcription apparatus, and the translation machinery in bacteria for stationary phase survival. Genes Cells 4, 135-143.

Ishihama, A. (2009). The nucleoid: an overview. In EcoSal Escherichia coli and Salmonella: Cellular and Molecular Biology. Edited by A. Boek and others. Washington, DC: American Society for Microbiology.

Ishihama, A. (2010). Prokaryotic genome regulation: multi-factor promoters, multi-target regulators and multi-factor networks. FEMS Microbiol Rev, Apr 14 [Epub ahead of print] doi:10.1111/j.15746976.2010.00227.x

Jishage, M., Iwata, A., Ueda, S. \& Ishihama, A. (1996). Regulation of RNA polymerase sigma subunit synthesis in Escherichia coli: intracellular levels of four species of sigma subunit under various growth conditions. J Bacteriol 178, 5447-5451.

Jubelin, G., Vianney, A., Beloin, C., Ghigo, J.-M., Lazzaroni, J.-C., Lejeune, P. \& Dorel, C. (2005). CpxR/OmpR interplay regulates curli gene expression in response to osmolarity in Escherichia coli. J Bacteriol 187, 2038-2049.

Kolb, A., Kotlarz, D., Kusano, S. \& Ishihama, A. (1995). Selectivity of the Escherichia coli RNA polymerase $\sigma^{38}$ for overlapping promoters and ability to support CRP activation. Nucleic Acids Res 23, 819-826.

Lacqua, A., Wanner, O., Colanglo, T., Martinotti, M. G. \& Landini, P. (2006). Emergence of biofilm-forming subpopulations upon exposure of Escherichia coli to environmental baceriophages. Appl Environ Microbiol 72, 956-959.

Latasa, C., Roux, A., Toledo-Arana, A., Ghigo, J. M., Gamazo, C., Penadés, J. R. \& Lasa, I. (2005). BapA, a large secreted protein required for biofilm formation and host colonization of Salmonella enterica serovar Enteritidis. Mol Microbiol 58, 1322-1339.

Loferer, H., Hammar, M. \& Normark, S. (1997). Availability of the fibre subunit CsgA and the nucleator protein CsgB during assembly of fibronection binding curli is limited by the intracellular concentration of the novel lipoprotein CsgG. Mol Microbiol 26, 11-23.

Maeda, H., Jishage, M., Nomura, T., Fujita, F. \& Ishihama, A. (2000). Extracytoplasmic function sigma subunits, sigma E and sigma FecI, of
Escherichia coli: promoter selectivity and intracellular levels. J Bacteriol 182, 1181-1184.

Minagawa, S., Ogasawara, H., Kato, A., Yamamoto, K., Eguchi, T., Mori, H., Ishihama, A. \& Utsumi, R. (2003). Identification and molecular characterization of the $\mathrm{Mg}$ (II) stimulon of Escherichia coli. J Bacteriol 185, 3696-3702.

Murakami, K., Fujita, N. \& Ishihama, A. (1996). Transcription factor recognition surface on the RNA polymerase a subunit is involved in contact with the DNA enhancer element. EMBO J 15, 4358-4367.

Navarre, W.W., Porwollik, S., Wang, Y., McClelland, M., Rosen, H., Libby, S. J. \& Fang, F.C. (2006). Selective silencing of foreign DNA with low GC content by the H-NS protein in Salmonella. Science 313, 236-238.

Niba, E. T. E., Naka, Y., Nagase, M., Mori, H. \& Kitakawa, M. (2007). A genome-wide approach to identify the genes involved in biofilm formation in E. coli. DNA Res 14, 237-246.

Ogasawara, H., Hasegawa, A., Kanda, E., Miki, T., Yamamoto, K. \& Ishihama, A. (2007a). Genomic SELEX search for target genes under the control of PhoQP-RstBA signal relay cascade. J Bacteriol 189, 4791-4799.

Ogasawara, H., Ishida, Y., Yamada, K., Yamamoto, K. \& Ishihama, A. (2007b). PdhR (pyruvate dehydrogenase complex regulator) controls the respiratory electron transport system in Escherichia coli. J Bacteriol 189, 5534-5541.

Olsen, A., Arnqqvist, A., Hammar, H., Sukupolvi, S. \& Normark, S. (1993). The RpoS sigma factor relieves H-NS-mediated transcriptional repression of $\operatorname{csg} A$, the subunit gene of fibronectin-binding curli in Escherichia coli. Mol Microbiol 7, 523-536.

Otto, K. \& Silhavy, T. J. (2002). Surface sensing and adhesion of Escherichia coli controlled by the Cpx-signaling pathway. Proc Natl Acad Sci U S A 99, 2287-2292.

Pedersen, A. G., Jensen, L. J., Brunak, S., Sterfeldt, H. H. \& Ussery, D. W. (2000). A DNA structural atlas for Escherichia coli. J Mol Biol 299, 907-930.

Pogliano, J., Lynch, A. S., Berlin, D., Lin, E. C. C. \& Beckwith, J. (1997). Regulation of Escherichia coli cell envelope proteins involved in protein folding and degradation by the Cpx two-component system. Genes Dev 11, 1169-1182.

Pratt, L. A. \& Silhavy, T. J. (1995). Identification of base pairs important for OmpR-DNA interaction. Mol Microbiol 17, 565-573.

Pratt, L. A. \& Silhavy, T. J. (1998). Crl stimulates RpoS activity during stationary phase. Mol Microbiol 29, 1225-1236.

Prigent-Combaret, C., Vidal, O., Dorel, C. \& Lejeune, P. (1999). Abiotic surface sensing and biofilm-dependent regulation of gene expression in Escherichia coli. J Bacteriol 181, 5993-6002.

Prigent-Combaret, C., Prensier, G., Le Thi, T. T., Vidal, O., Pejeunne, P. \& Dorel, C. (2000). Developmental pathway for biofilm formation in curli-producing Escherichia coli strains: role of flagella, curli and colanic acid. Environ Microbiol 2, 450-464.

Prigent-Combaret, C., Brombacher, E., Vidal, O., Ambert, A., Lejeune, P., Landini, P. \& Dorel, C. (2001). Complex regulatory network controls initial adhesion and biofilm formation in Escherichia coli via regulation of the csgD gene. J Bacteriol 183, 7213-7223.

Raivio, T. L. \& Silhavy, T. J. (1997). Transduction of envelope stress in Escherichia coli by the Cpx two-component system. J Bacteriol 179, 7724-7733.

Ren, D., Bedzyk, L. A., Thomas, S. M., Ye, R. W. \& Wood, T. K. (2004). Gene expression in Escherichia coli biofilms. Appl Microbiol Biotechnol 64, 515-524.

Rice, P. A., Yang, S., Mizuuchi, K. \& Nash, H. A. (1996). Crystal structure of an IHF-DNA complex; a protein-induced DNA U-turn. Cell 87, 1295-1306. 
Robbe-Saule, V., Jaumouille, V., Prevost, M.-C., Gaudagnini, S., Talhouarne, C., Mathout, H., Kolb, A. \& Norel, F. (2006). Crl activates transcription initiation of RpoS-regulated genes involved in the multicellular behavior of Salmonella enterica serovar typhimurium. J Bacteriol 188, 3983-3994.

Romling, U., Sierralta, W. D., Eriksson, K. \& Normark, S. (1998). Multicellular and aggregative behavior of Salmonella typhimurium strains is controlled by mutations in the agfD promoter. Mol Microbiol 28, 249-264.

Romling, U., Rohde, M., Olsen, A., Normark, S. \& Reinkoster, J. (2000). AgfD, the checkpoint of multicellular and aggregative behaviour in Salmonella typhimurium regulates at least two independent pathways. Mol Microbiol 36, 10-23.

Schembri, M. A., Kjaergaard, K. \& Klemm, P. (2003). Global gene expression in Escherichia coli biofilms. Mol Microbiol 48, 253-267.

Shimada, T., Hirao, K., Kori, A., Yamamoto, K. \& Ishihama, A. (2007). RutR is the uracil/thymine-sensing master regulator of a set of genes for synthesis and degradation of pyrimdines. Mol Microbiol 66, 744757.

Simm, R., Morr, M., Kader, A., Nimtz, M. \& Romling, U. (2004). GGDEF and EAL domains inversely regulate cyclic d-GMP levels and transition from sessility to motility. Mol Microbiol 53, 1123-1134.

Simons, R. W., Houman, F. \& Kleckner, N. (1987). Improved single and multicopy lac-based cloning vectors for protein and operon fusions. Gene 53, 85-96.

Snyder, W. B., Davis, L. J., Danese, P. N., Cosma, C. L. \& Silhavy, T. J. (1995). Overproduction of NlpE, a new outer membrane lipoprotein, suppresses the toxicity of periplasmic LacZ by activation of the Cpx signal transduction pathway. J Bacteriol 177, 4216-4223.

Sugiura, M., Aiba, H. \& Mizuno, T. (2003). Identification and classification of two-component systems that affect rpoS expression in Escherichia coli. Biosci Biotechnol Biochem 67, 1612-1615.

Sutherland, I. (2001). Biofilm exopolysaccharides: a strong and sticky framework. Microbiology 147, 3-9.

Suziedeliene, E., Suziedelis, V., Garbenciute, V. \& Normark, S. (1999). The acid-inducible asr gene in Escherichia coli: transcriptional control by the phoBR operon. J Bacteriol 181, 2084-2093.
Tanaka, K., Kusano, S., Fujita, N., Ishihama, A. \& Takahashi, H. (1995). Promoter determinants for Escherichia coli RNA polymerase holoenzyme containing $\sigma^{38}$ (the rpoS gene product). Nucleic Acids Res 23, 827-834.

Umezawa, Y., Ogasawara, H., Shimada, T., Kori, A. \& Ishihama, A. (2008). The uncharacterized YdhM is the regulator of the nemA gene, coding for N-ethylmaleimide reductase. J Bacteriol 190, 5890-5897.

Vianney, A., Jubelin, G., Renault, S., Dorel, C., Lejeune, P. \& Lazzaroni, J. C. (2005). Escherichia coli tol and rcs genes participate in the complex network affecting curli synthesis. Microbiology 151, 2487-2497.

Vidal, O., Longain, R., Prigent-Combaret, C., Dorel, C., Hooreman, M. \& Lejeune, P. (1998). Isolation of an Escherichia coli K-12 mutant strain able to form biofilms on inert surfaces: involvement of a new $o m p R$ allele that increases curli expression. J Bacteriol 180, 2442-2449.

Wang, X., Preston, J. F., III \& Romeo, T. (2004). The pgaABCD locus of Escherichia coli promotes the synthesis of a polysaccharide adhesin required for biofilm formation. J Bacteriol 186, 2724-2734.

Wang, X., Smith, D. R., Jones, J. W. \& Chapman, M. R. (2007). In vitro polymerization of a functional Escherichia coli amyloid protein. J Biol Chem 282, 3713-3719.

Yamamoto, K. \& Ishihama, A. (2006). Characterization of copperinducible promoters regulated by $\mathrm{CpxA} / \mathrm{CpxR}$ in Escherichia coli. Biosci Biotechnol Biochem 70, 1688-1695.

Yamamoto, K., Hirano, K., Ohshima, T., Aiba, H., Utsumi, R. \& Ishihama, A. (2005). Functional characterization in vitro of all twocomponent signal transduction systems from Escherichia coli. J Biol Chem 280, 1448-1456.

Zheng, D., Constantinidou, C., Hobman, J. L. \& Minchin, S. D. (2004). Identification of the CRP regulon using in vitro and in vivo transcriptional profiling. Nucleic Acids Res 32, 5874-5893.

Zogaj, X., Nimtz, M., Rohde, M., Bokranz, W. \& Romling, U. (2001). The multicellular morphotypes of Salmonella typhimurium and Escherichia coli produce cellulose as second component of the extracellular matrix. Mol Microbiol 39, 1452-1463.

Edited by: V. Sperandio 